\title{
Entre política e técnica: reversão, crítica e linguagem em projetos de desenvolvimento
}

\author{
Between politic and technique: reversion, critique and language in \\ development projects \\ Entre la política y la técnica: reversión, crítica y lenguaje en proyectos de \\ desarrollo
}

\author{
Guilherme Francisco Waterloo Radomsky ${ }^{1}$
}

Recebido em 20/03/2018; revisado e aprovado em 03/08/2018; aceito em 10/08/2018

DOI: http://dx.doi.org/10.20435/inter.v0i0.1893

\begin{abstract}
Resumo: O artigo examina o tema do desenvolvimento em perspectiva crítica. Além do seu fracasso ao longo de décadas, mostra que o campo assiste a novas formas de instrumentalização técnica que procuram mitigar sem sucesso aspectos da violência do desenvolvimento. Em geral, a linguagem dos atores principais continua a se apresentar a partir de um lugar de fala que articula hierarquia, saber e poder.
\end{abstract}

Palavras-chave: desenvolvimento; discurso; política econômica.

\begin{abstract}
The article examines the issue of development in a critical perspective. In addition to its failure for decades, it shows that the field is witnessing new forms of technical instrumentalization that seek to mitigate aspects of development violence without success. In general, the language of the main actors continues to present itself articulating hierarchy, knowledge and power.

Keywords: development; discourse; economic policy.

Resumen: El artículo examina el tema del desarrollo en perspectiva crítica. Además de su fracaso a lo largo de décadas, muestra que el campo asiste a nuevas formas de instrumentalización técnica que buscan mitigar sin éxito aspectos de la violencia del desarrollo. En general, el lenguaje de los actores principales continúa presentándose a partir de un lugar que articula jerarquía, saber y poder.
\end{abstract}

Palabras clave: desarrollo; discurso; política económica.

\section{INTRODUÇÃO}

Em recente artigo, Sallum Júnior e Goulart (2016) examinaram a agenda de desenvolvimento no Brasil nos governos dos presidentes Fernando Henrique Cardoso e Luiz Inácio Lula da Silva. Esse assunto, nesses últimos anos, com guinadas políticas que o país tem vivido, parece recobrar uma relevância ainda maior, especialmente se considerarmos o quanto isto pode estar no centro do debate sobre estabilidade política e inclusão social. No texto mencionado, lemos que a oposição marcante entre liberalismo e desenvolvimentismo, muitas vezes enfatizada como dinamizadora das opções eleitorais e das alianças partidárias, pode encontrar na nossa história recente situações em que estaríamos mais próximos de uma síntese e solução tipo "liberal-desenvolvimentismo". Observe-se bem que justamente um dos autores do artigo havia sido um pouco mais enfático a respeito dessa disputa em outro momento, sugerindo que o Brasil organizava estratégias ora mais liberais, ora mais desenvolvimentistas (SALLUM JR., 2001).

Portanto considerar que, no país, há alterações de rumo que apostam em soluções conciliadoras (algo de liberal nos governos mais voltados ao desenvolvimentismo e programas que se pode entender como desenvolvimentistas em governos liberais) pode fazer eco com o que as ciências sociais brasileiras já produziram sobre certas características de nossa vida política.

\footnotetext{
${ }^{1}$ Universidade Federal do Rio Grande do Sul (UFRGS), Porto Alegre, Rio Grande do Sul, Brasil.
} 
Para o tema do desenvolvimento em questão, Fonseca (2004) faz um estudo de sua gênese no pensamento brasileiro e mostra as variadas contribuições, desde o positivismo mais voltado à intervenção (quem sabe autoritário), passando por influências nacionalistas, chegando até orientações focadas em política monetária. Uma pista relevante dessa gênese está no fato de que Fonseca (2004) escreve que foi exatamente o desenvolvimentismo que unificou e deu sentido à combinação de diferentes correntes de pensamento. Aliás, a combinação de ideologias na história do país, tais como autoritarismo e liberalismo, certamente vinculadas às orientações acerca das políticas de desenvolvimento, não é algo sem expressão, sendo documentada e objeto de reflexão e debate por parte de pesquisadores e escritores.

Instigado por essa interpretação, o leitor poderia se perguntar se não estamos curiosamente diante de uma inversão daquela polêmica proposta de Žižek (2008) sobre a visão paralaxe: dois pontos de vista que nunca se encaixam e nunca encontram uma síntese passível de superar tese e antítese, no Brasil sempre "se dá um jeito" e aqui a superação parece ocorrer antes da contradição aparecer. Paralaxe, explica o filósofo esloveno, é o deslocamento aparente de um objeto de acordo com a alteração de posição do observador, e Žižek pretende que esta seja uma estratégia de análise para tensões, lacunas, incoerências, antinomias irredutíveis. Liberaldesenvolvimentismo seria, antes de tudo, uma possibilidade política característica de um país que nunca foi totalmente liberal, que jamais optou pela ação desenvolvimentista definitivamente antiliberal. O que testemunhamos são nuances, ênfases, políticas paradoxais, em que pese às diferenças que também precisam ser salientadas.

Uma conhecida palestra de F. H. Cardoso é sugestiva quanto a isto. Em O modelo político brasileiro, reproduzida em Cardoso (1972), apesar de supor que o golpe de 1964 não indicava uma volta ao passado, e sim uma rearticulação fundamentada em alterações do modelo de desenvolvimento, no seu entendimento, se bem observo, as ações convergem para a disputa por estilo ou modo de desenvolvimento (CARDOSO, 1972), e não a respeito de optar pelo desenvolvimento ou não.

O regime que terminou por se instaurar não teve o caráter de uma volta ao passado, como pensam alguns analistas que insistem na continuidade da história contemporânea brasileira desde 1930, com o interregno de 1945-1964. Pelo contrário, ele expressa uma rearticulação política que se baseia em alterações no modelo social e econômico de desenvolvimento que prevalecia anteriormente. (CARDOSO, 1972, p. 52).

Quase quinze anos depois, Bolívar Lamounier (1985, p. 125) viria a apontar que

Com efeito, ao completar 10 anos, o regime de 1964 já correspondia à mais longa experiência de governo autoritário jamais vivida pelo Brasil independente, caracterizada pela ocupação direta e corporativa do poder pelos militares. A não menos ostensiva aliança destes com o ramo "internacionalista" da tecnocracia econômica e civil e com os interesses empresariais de grande porte, nacionais e estrangeiros, tornava inequívoca a implantação de um novo modelo de organização estatal e de crescimento econômico.

Poderíamos afirmar que o desenvolvimento no Brasil se constitui como uma linguagem e o que mudaria é como fazer operar, quem se beneficia, quais mecanismos são ativados, e nunca estamos diante de sua crítica radical ou negação? Pelo menos desde meados das décadas de 1930 e 1940, a sensação é que o desenvolvimento não deixa de ser propulsor da dinâmica política, seja em orientação próxima ao liberalismo, seja por qualquer ação mais intervencionista. 
A discussão em torno do quanto as dimensões complexas no âmbito de políticas e de estudos sobre o desenvolvimento remete a questões de linguagem e significado faz parte do núcleo das reflexões deste texto. Procuro analisar o problema das ações que orientam políticas e programas de desenvolvimento e como elas têm levado, em geral, a um leque variado de respostas de movimentos sociais, grupos organizados ou mesmo no campo acadêmico, das quais destaco duas. De um lado, a crítica que se manifesta na recusa do desenvolvimento e, de outro, aquela que mostra situações em que, nas interfaces dos projetos com comunidades, se apresentam atores locais aderindo ao desenvolvimento e paulatinamente transformam seu conteúdo. Algumas referências têm mostrado que, na medida em que é assimilado e assumido por grupos sociais, a transformação do próprio programa ou projeto de desenvolvimento é tamanha que surge a questão: é possível ainda falar em desenvolvimento nesses casos? Busco mostrar que, entre estar contra e estar a favor do desenvolvimento, há um espaço intersticial no qual se insere uma espécie de desenvolvimento reverso.

Examino também como que, apesar das dimensões violentas com que muitas vezes se apresentam projetos e programas de desenvolvimento em relação a comunidades locais, certos fenômenos têm despertado a atenção de pesquisadores para um conjunto de mecanismos técnicos que mitigam conflitos. Assim, são "tecnologias" que parecem organizar a justificativa dos processos de desenvolvimento por recorrerem à explicação da ciência e ao discurso da necessidade de medidas político-econômicas. Caberá indagar, portanto, sob que pontos de vista reproduzem formas de dominação e poder.

Em cada uma dessas dimensões em que a análise é realizada, recorro a um conjunto de estudos de referência na área, alguns dos quais em citações mais longas funcionam não somente como suporte analítico, mas especialmente como relato ou testemunho. Tais excertos, desse modo, são também manifestações concretas de processos ocorridos ou em andamento, e seu foco aqui, como testemunho, aponta para e exemplifica algo característico dos processos de desenvolvimento contemporâneos - característico, talvez peculiar e ao mesmo tempo em que reverbera em muitas outras ocasiões, porém não necessariamente aspira a ser representativo do todo.

\section{NADA MUDOU NAS POLÍTICAS DE DESENVOLVIMENTO?}

As teorias do desenvolvimento contemporâneas são muito enfáticas nas mudanças de orientação e perspectiva relativas aos processos de induzir transformações sociais. Desde as que falam no desenvolvimento como liberdade, passando pelas apelativas da participação e da governança, até as locais e territoriais, ou de gênero, sustentável e centrado nas pessoas, o sentimento de que algo mudou (ou que deve mudar) é sintomático (RIST, 2008; ESTEVA, 1992). Certamente é sintomático dos fracassos da mudança induzida impetrada no começo da "era do desenvolvimento" (meados do séc. XX, com foco em crescimento, programas elaborados ao estilo top-down, produtivismo, confiança na disseminação de instituições da modernidade etc.), mas demonstram também como este é um tema refém do "dever-ser" ${ }^{2}$ e, portanto, sua permanência só é possível se houver busca incessante de renovação e tentativas com promessas redentoras.

\footnotetext{
${ }^{2}$ Parte da literatura crítica voltada ao tema (FERGUSON, 1990; RIST, 2008) considera que "como as coisas devem ser" toma conta dos textos de pesquisadores da área, mais do que "como as coisas realmente são".
} 
E o que mudou? Vejamos um caso que examina como as coisas realmente são.

Desde minhas primeiras experiências no Banco Mundial, eu aprendi que desenvolvimento não pode ser medido com simples dados como crescimento ou PIB. Ao invés, desenvolvimento deveria ser entendido como um conjunto complexo de práticas costurados no tecido da vida cotidiana, tanto em distritos pobres como ricos, do sul global e do norte. Além do mais, a maior parte do capital emprestado para os governos do Sul em nome do desenvolvimento vai através de bancos do Norte pra que os do Sul comprem produtos das empresas do Norte. [...] O papel do Banco mundial é central na acumulação de riqueza dos países do primeiro mundo [...]. Uma estatística alarmante que quase não mudou desde a sua criação há mais de 60 anos atrás é que muito do capital emprestado pelo Banco Mundial passa através das mãos dos governos dos países do Sul e viaja direto para empresas das nações do Norte, os principais atores do desenvolvimento. (GOLDMAN, 2005, p. xi) ${ }^{3}$.

Michael Goldman, que realizou pesquisa dentro da organização mencionada no trecho acima, sugere que a preocupação do Banco Mundial se dá menos com os potencialmente beneficiários. Ao indagar um funcionário importante do Banco sobre um projeto específico na Ásia, o etnógrafo recebe a resposta de que as coisas são assim mesmo: ao pensar um projeto envolvendo, por exemplo, melhoria do sistema de água de uma comunidade rural indiana primeiro se pensa quais empresas europeias e americanas podem suprir tal necessidade de infraestrutura e como ou quanto ganharão.

Não é à toa que a literatura hoje conhecida pela denominação de pós-desenvolvimento, apareceu como resultado de um círculo vicioso de tentativa-fracasso de programas com o componente do cinismo, ora mais mascarado, ora mais explícito ${ }^{4}$. Kapoor (2008) entende que é difícil escapar de considerar que a cultura do desenvolvimento atual é marcada por quatro eixos: $i$. Necessidades básicas (segundo o autor, a noção supõe uma naturalidade universal do desenvolvimento e enseja um comportamento paternalista); ii. Ajuste estrutural (funciona a distância); iii. Boa governança, informação, desenvolvimento gerencial, accountability e framework legal e; iv. Moralismo e direitos humanos (também universalistas).

Porém, quando se lê tais indicações, a incoerência gritante com o relato de Goldman é enorme, particularmente aos eixos iii e iv. Daí que alguns dos estudos mais recentes de crítica do desenvolvimento procuram sustentar não apenas os efeitos colaterais dos projetos e programas, tampouco as tentativas malsucedidas que redundaram em fracassos por conta de problemas imprevistos. O que se projeta é uma violência mesma do desenvolvimento, do início do projeto ao fim em suas consequências (SYLVESTER, 2006; PAREDES PEÑAFIEL, 2017; PARFITT, 2009).

\subsection{Desenvolvimento em reversão}

No dia cinco de junho de 2009, ocorreu em uma localidade denominada com sutileza de La Curva del Diablo (região de Uctubamba, no Peru) o que ficou conhecido como o Massacre de Bagua. A polícia nacional peruana e os membros das etnias Awajun e Wanpis conflituaram provocando a morte de mais de trinta pessoas entre policiais e indígenas, somando muitos feridos e desaparecidos. Quase dois meses antes do acontecimento, foram vividos intensos protestos

\footnotetext{
${ }^{3}$ Tradução própria.

${ }^{4}$ O pós-desenvolvimento tem uma produção vasta e não será possível citar todos os autores, mas cabe mencionar os trabalhos de Escobar (2007), Rist (2008), Esteva (1992), Rahnema e Bawtree (1997), além dos balanços críticos de Storey (2000), Ziai (2007), Brigg (2002) e outros.
} 
contra decretos legislativos excepcionais do então presidente Alan García, com a finalidade da concretização do Tratado de Livre Comércio (TLC) com os EUA.

$\mathrm{Na}$ verdade, sabia-se que esses atos executivos tinham relação direta com abertura de espaços para exploração mineral e de outros recursos na floresta amazônica, já que García havia escrito artigos na imprensa nacional sobre a ociosidade das terras e dos índios, e que não era cabível deixar aproveitar recursos valiosos para o desenvolvimento do país. Num dos seus discursos, o então presidente chama essa atitude como semelhante ao comportamento do perro del hortelano, aquele que não usufrui, mas que não deixa os outros usufruírem (ver adiante). Somente para ilustrar, um trecho é significativo:

Mas este crescimento, tanto como o desenvolvimento, necessita de um grande espaço e grau de investimento, e para isto é essencial um TLC. Este nos ajudará a manter uma democracia firme, uma democracia que se ocupe dos mais necessitados e que venha a ser provedora de trabalho aos desempregados. É importante demonstrar ao mundo que uma democracia com investimento leva ao desenvolvimento. E o desenvolvimento não se consegue sem fazer nada e sem abrir as portas ao mercado ${ }^{5}$.

Não é paradoxal que o termo democracia aqui esteja sendo utilizado numa cadeia de significantes (LACLAU; MOUFFE, 1985) e que conduza o pensamento para o inverso do que é intuitivo? Ou seja, enquanto democracia e desenvolvimento são sustentados como articulados (e sem se precisar dar conteúdo às palavras), os atos legislativos excepcionais e a incapacidade dos movimentos sociais serem ouvidos por atores do governo indicam que ou democracia é um termo tão amplo que se pode fazê-lo significar muitas coisas diferentes, ou que a democracia se torna contraditoriamente um empecilho à emancipação política, uma vez que os princípios da representação seriam arma ideológica de domínio.

O material relativo ao Massacre de Bagua foi examinado em outro contexto (PAREDES PEÑAFIEL; RADOMSKY, 2011), e cabe aqui retomar unicamente para destacar uma fala proferida por Alberto Pizango (2009), então presidente da Associación Interétnica de Desarrollo de la Selva Amazónica (AIDESEP), no que tange ao desenvolvimento.

Alguns dias após o evento violento do confronto, provocado de todos os lados, Pizango exclamou em uma entrevista coletiva à imprensa:

Nós não estamos contra o desenvolvimento, tal como nos acusam. Nós queremos o desenvolvimento, mas desde a nossa própria perspectiva [...]. De que nos serve ter luz, água, telefones celulares, se vemos nossas comunidades destruídas e inundadas por pragas sociais? (PIZANGO, 2009, p. 4). ${ }^{6}$

Quem pode falar, tal como Spivak (2010) manifestou em seu conhecido ensaio? O que interessa neste momento é que contra a universalidade supostamente inclusiva - mas muito excludente - do depoimento anterior, Pizango (2009) sugere uma concepção lugarizada do desenvolvimento, sem procurar uma versão que seja válida para todos e tampouco anular a dos outros - desde que não interfira no seu mundo local.

Ainda assim, como têm sido a recepção e a intervenção de forças institucionais menos propensas a tal diálogo e abertura? Se há na fala do líder comunitário Pizango (2009) apelo pela

\footnotetext{
${ }^{5}$ Palavras de Alan García durante a reunião de abril de 2007 nos EUA, transcrita e veiculada no portal da Casa Branca. Tradução própria.

${ }^{6}$ Tradução própria.
} 
legitimidade dos diferentes povos nativos apresentarem pontos de vista sobre como o seu mundo é e deve ser, já vimos que o então presidente García preferia manter seu tom de sapiência do que seja correto e qual o caminho para o Peru. García não poupa em suas investidas nem mesmo aqueles que um dia projetaram um futuro muito diferente para o mundo.

Recorde, perro del hortelano", o ensinamento de Lenin em seu texto "Capitalismo de Estado e imposto em espécie: "Devem vir os capitalistas, ganharão muito, mas nos ensinarão o caminho da técnica e do desenvolvimento". Foi uma mudança de rumo genial, mas Lenin morreu pouco depois. Hoje, o perro del hortelano se entusiasma gritando "nem um passo atrás" e se esquece de Lenin, que aconselhou: "Um passo atrás para dar dois adiante". (GARCÍA PÉREZ, 2007, p. A6).8

Se Lenin pode ser bem apropriado para usos e abusos, "e os capitalistas nos ensinarão o caminho da técnica e do desenvolvimento, uma mudança de rumo", com García expõe no trecho acima, vemos que quando se trata do desenvolvimento - e aparentemente se deseja o desenvolvimento em ambos os casos - pequenas diferenças fazem grande diferença, como escreveram Mary Douglas e Baron Isherwood (DOUGLAS; ISHERWOOD, 2006). Assim, questões de linguagem e significado importam mais do que geralmente pensamos.

Entre uma e outra manifestação, encontramo-nos em uma situação que foi observada por alguns filósofos como típica do que seja o problema político no Ocidente: o que para uns (Alberto Pizango e comunidades indígenas) pode ser fala que se pretende ser ouvida e participada no diálogo, para outros (Alan García) é ruído e não constitui palavra que deva ser levada em consideração. Estas não são, na realidade, pessoas que deveriam estar no espaço de opinião democrática, conforme análises de Chauí (1980) e Rancière (1996). Segundo Rancière (1996), a política diz respeito a um litígio sobre que incomensurabilidades, disputas de princípio e sobre quem "é contado" enquanto de fato fazendo parte do mundo e da possibilidade de integrar o debate político.

A ideia de que há perspectivas sobre como deve ser o desenvolvimento está o tempo todo em risco, pois se choca com o falar e fazer em nome do desenvolvimento, dos que falam e decidem pelos outros. Um dos pontos delicados está no próprio âmago das teorias do desenvolvimento, pois se trata de mostrar que

[...] falar do desenvolvimento bottom-up é confundir meios e fins do desenvolvimento. Se o objetivo do desenvolvimento é definido como ampliar as escolhas das pessoas, isso pressupõe [citando Cowen e Shenton] 'desejo e capacidade de escolher, assim como conhecimento da escolha possivel'. (NUSTAD, 2007, p. 40).

Nas palavras de outro pesquisador, Aram Ziai (2015), os autores Cowen e Shenton, citados na passagem, utilizam o termo 'trusteeship' para assinalar o apelo dos "especialistas em desenvolvimento para legitimamente planejar e implementar intervenções sociais baseadas em conhecimento [técnico] para o bem comum e em particular para o benefício dos mais pobres sem pedir sua permissão" (ZIAI, 2015, p. 835).

\footnotetext{
${ }^{7}$ Esta expressão possui riqueza literária no original em espanhol, pois é oriunda da obra do poeta e dramaturgo Lope de Vega, que viveu na virada do séc. XVI para o séc. XVII. Preferi mantê-la tal como escreve o então presidente do Peru, significando em língua portuguesa "o cachorro do horticultor". Trata-se de uma referência constante àquele que não usufrui e tampouco deixa os outros usufruírem de algo.

${ }^{8}$ Tradução própria.
} 
Em um artigo originalmente publicado no início dos anos 1990, a antropóloga Dominique Perrot (2008) relata um projeto de desenvolvimento local que ilustra alguns dos elementos antes brevemente mencionados por Alberto Pizango.

Ora, o trabalho de desenvolvimento junto aos povos autóctones consistiu acima de tudo, até recentemente, em modificar com a ajuda de projetos a economia indígena de maneira com que ela esteja em contato com o mercado, às vezes com a oferta de serviços de saúde e educação. Certamente existem exceções, mas poderão elas ser ainda designadas pelo rótulo "projetos de desenvolvimento"? Não seriam elas melhor compreendidas se procurarmos nelas as alternativas ao desenvolvimento? Assim se deu o caso exemplar do contrato que uniu o Conselho dos Aguaruna e Huambisa no Peru a um organismo composto por profissionais «brancos» (Desenvolvimento do Alto-Marañon, o DAM). A idéia era inverter, com o aval dos índios, as prioridades clássicas do desenvolvimento: os projetos de agricultura, saúde e marketing foram considerados como simples meios (ou pretextos) implementados para atingir uma finalidade: a constituição de uma organização autóctone, representativa e autônoma. O DAM havia estimado um período de dez anos, os quais seriam necessários para atingir esse objetivo. Ao final de nove anos, o Conselho havia se tornado suficientemente forte e crível para poder dispensar os serviços do DAM nas relações que ele mantinha com os funcionários do governo, os missionários e os colonos. Nessa mesma ordem de ideias, certas organizações indígenas que representam suas comunidades estão produzindo um conhecimento sociológico aprofundado e complexo das mudanças políticas e organizacionais da ajuda. (PERROT, 2008, p. 223-4).

Esse trecho relata uma desconstrução exemplar do desenvolvimento. O risco sempre em jogo é que um pesquisador ou formulador de políticas públicas apressado conclua: "veja, os índios, no fundo, querem o desenvolvimento; não apenas aceitaram a mediação como também abraçaram o projeto". Contudo, com qual objetivo? Para dar outro fim. Eis o ponto: o que se passou foi uma reversão do processo de tal modo que a proposta "de desenvolvimento" original não possuía mais significado: era meio para outro objetivo.

Talvez alguns elementos a mais de etnologia possam auxiliar. Se o depoimento de Alberto Pizango (2009) poderia suscitar alguns dos problemas introduzidos pelo perspectivismo hoje propalado em antropologia, a organização peruana sugere o que o antropólogo Stuart Kirsch denominou de antropologia reversa (KIRSH, 2006). O que se destaca no final do trecho acima é que a organização indígena produz conhecimento sociológico a respeito do desenvolvimento e da ajuda internacional (WAGNER, 2010; GOLDMAN, 2011). No entanto este saber - e este é o ponto - não é a mesma sociologia praticada nas universidades, aí justamente que perspectivas nunca implicam simetria de posições ou pensamentos (STRATHERN, 2006).

Caso o procedimento faça mais do que o velho relativizar típico da antropologia é porque ele não se contenta com dizer que seja uma diferente maneira de ver o desenvolvimento, mas o que nós mesmos entendemos ou podemos vir a entender a respeito do que sejam desenvolvimento, conhecimento e sociologia se altera drasticamente (HOLBRAAD; PEDERSEN, 2017).

O que prefiro destacar dessa interação é que o desenvolvimento é reordenado e se torna utilizado como alternativa contra ele próprio, implicando uma reflexividade do processo, o que poderia nos levar a pensar que o trabalho dos mediadores e da organização em constituição funciona como uma forma de contra-trabalho (counter-work), como bem observaram Arce e Long (2000). Para o que interessa a esta reflexão, o contra-trabalho poderíamos aproximar a algo a ser denominado de contra-desenvolvimento. Essa forma de oposição ao desenvolvimento sugere conflito simultâneo a um paralelo engajamento com o problema do desenvolvimento 
local, produzindo um efeito de mudança justamente em razão do envolvimento na questão, e não somente uma recusa. Isto tem por consequência a compreensão de que - ainda seguindo Arce e Long (2000) - toda vez que uma receita é aplicada em dado contexto, o envolvimento de atores sociais concretos necessariamente modifica a própria receita em alguma medida. E assim,

Quando um projeto é levado de um lugar a outro, de um agente a outro, versões de poder são produzidas. [...] A aquisição de novas formas de linguagem oriundas do Ocidente - se por imposição forçada, inserção insidiosa ou empréstimo voluntário - é parte do que faz serem possíveis novas possibilidades de ação em sociedades não-Ocidentais. (ASAD, 1993, p. 13).

Não parece ser possível isolar as dimensões de poder que igualmente podem ser reproduzidas. No entanto, há situações, tais como a exposta por Perrot (2008), em que forças sociais se alinham para uma articulação favorável aos povos locais. É um trabalho que se vale dos recursos do desenvolvimento, mas cuja finalidade é desmontar os planos originais, reestruturar o que se constrói, inverter prioridades e reverter finalidades.

\section{POLÍTICA, DEMONSTRAÇÕES TÉCNICAS E O DISCURSO DA NECESSIDADE}

Retornando ao caso do Brasil, se Sallum Jr. e Goulart (2016) examinavam tendências político-econômicas no país ao estilo "gangorra" (ora desenvolvimentismo, ora liberalismo) ou sintético (liberal-desenvolvimentista), podemos dizer que, desde 2003 ou 2004, o que ficou conhecido como novo-desenvolvimentismo ganhou efeito notável nos discursos acadêmicos e midiáticos. O leitor poderá ter estranhado que este ensaio tenha iniciado com uma reflexão sobre o desenvolvimento no Brasil que até então não foi recuperada, pois é justamente aqui que tais observações fazem sentido.

Apesar de as promessas do desenvolvimento serem antigas, a capacidade deste de se metamorfosear e de contagiar as emoções coletivas parece merecer destaque. Nos governos dos presidentes Lula e Dilma (entre 2003-2016), a possibilidade do salto para um patamar mais avançado na economia passava por opções de ênfase em política social, cooperação Sul-Sul, Programa de aceleração do crescimento e muitas outras frentes de intervenção, portanto com ação estatal mais efetiva. Após o início do governo de Michel Temer, observamos mudanças em relação aos aspectos anteriores, mas igualmente foi possível perceber a permanência no discurso do crescimento e do desenvolvimento.

O que cabe destacar é a capacidade do desenvolvimento em se tornar uma espécie de linguagem típica da política e da economia brasileira, mudando somente os mecanismos de ação, os setores econômicos ou grupos com maior privilégio, os incentivos e as leis vigentes. Governos de distintas posições no espectro político-partidário fazem uso de tal linguagem. É evidente que a mudança, a depender de qual transição de governo assistimos, não é pequena. O que se realça é tão somente o porquê de o desenvolvimento continuar a ser parte constitutiva do discurso e da agenda. Aqui estaríamos frente ao que Ribeiro (2008) sugeriu ser típico do desenvolvimento: um sistema de crenças tão basilar no Ocidente (RIST, 2008) que está para além das ideologias, isto é, ultrapassa disputas políticas e é uma narrativa geral e disseminada, capaz até mesmo de unir grupos sociais com metas e intenções muito distintas.

No entanto um apelo mais particular situa-se não tanto no nível dos aspectos emocionais e sedutores, mas sim no quanto o que vemos e temos que decidir em termos políticos (em propostas eleitorais, por exemplo) está num âmbito da eficiência demostrada, sobretudo científica. 
Para além de uma ampla narrativa, o ato de governar por meio das políticas de desenvolvimento parece ser paulatinamente mais ancorado nos procedimentos científicos - pelo menos na maneira como é apresentado e, nesse processo, a técnica (e não a política) entra como árbitra de decisões polêmicas.

Vale a pena uma breve inflexão ao pensamento de um sociólogo contemporâneo que auxilia a organizar essa problemática. Em artigo traduzido e publicado num periódico brasileiro, Luc Boltanski (2013) faz uma análise de quanto a ciência e a técnica se aliam aos dispositivos de gestão típicos do capitalismo contemporâneo para dar forma aos atuais mecanismos de dominação social. Após mostrar sinteticamente o que sejam os modos de dominação que optam pela violência, por ideologias (ou ambas e seus mecanismos) ${ }^{9}$, o autor inteligentemente identifica "[...] finalmente, um terceiro modo de dominação que eu chamo de gestionário [...]. [E]sse modo de dominação caracteriza, pelo menos como tendência, as formas de governança que se implementam nas democracias capitalistas contemporâneas" (BOLTANSKI, 2013, p. 445).

Observemos que a diferença dos dois modos anteriores, os elementos que governam a vida dos indivíduos são mais sutis, mesmo que se perfazendo na trilha dos imperativos. Ela ocorre pela justificativa da necessidade e se fundamenta nos usos da ciência como portadora da verdade. O que justifica este problema para as questões envolvendo o desenvolvimento, ainda que Boltanski não se volte ao tema? Eis que

[...] verifica-se a instrumentalização da ciência econômica por líderes políticos e econômicos. Esta instrumentalização consiste - numa explicação rápida - em dar-Ihe visibilidade pública e torná-la a principal ferramenta capaz de escolher, entre tudo o que acontece, os eventos relevantes, e também em dar-Ihes significado, encaixando-os em um quadro unificado e associando-os a certos mecanismos. [...] E o tipo de trama que ela pratica apela, fundamentalmente, não apenas - como na história - à noção de causalidade, mas, sobretudo, de necessidade. [...] o terceiro ponto diz respeito ao uso político que é feito destas técnicas. (BOLTANSKI, 2013, p. 442).

Portanto, sem que pareça, enquanto a instrumentalização diz respeito à técnica despolitizando os problemas sociais, ela só pode ser analisada por nós como sendo profundamente política, mesmo que isto signifique, como bem aborda o autor, que se trata de um uso político da técnica. Há ainda outros elementos associados. Boltanski (2013) infere que tal processo constitui uma dominação sem sujeito, isto é, "ela é baseada em dispositivos dos quais indivíduos ou grupos podem tirar maior ou menor proveito" (Boltanski, 2013, p. 449).

Do ponto de vista dos estudos críticos do desenvolvimento, foi James Ferguson quem melhor apreendeu essa mecânica, para qual se apela para a necessidade da resposta tecno-científica quanto a dilemas do subdesenvolvimento, despolitizando as relações e criando obstáculos para críticas sociais. Os problemas advindos de políticas de desenvolvimento, que, após algum tempo, podem ser consideradas equivocadas, mostram que medidas intencionais para transformação econômica podem ter consequências variadas, interpretadas como meros efeitos colaterais indesejados, fabricadas por ações diversas de uma constelação de atores bem intencionados. Acabam resultando em fins instrumentais e que estes, mesmo se não estavam na finalidade

\footnotetext{
${ }^{9}$ O autor francês faz um belo passeio pelas características dos distintos modos de dominação, com uso da violência física e por meio de ideologias, os quais não serão abordados neste artigo. Remeto o leitor para o artigo de Boltanski (2013) ou para o livro original do ano de 2009 (De la critique) no qual elabora mais detalhadamente seus argumentos.
} 
inicial, podem expandir o poder de alguns grupos sociais específicos ou do Estado. É justamente essa constelação resultante e sem autoria claramente definida que o antropólogo denomina de "máquina anti-política" (FERGUSON, 1990).

\subsection{A técnica e a política no crescimento econômico}

Contudo, qual a razão de se fazer este percurso analítico para os propósitos da argumentação deste texto? Um rumo não exatamente esperado passou a ser seguido em torno dos anos 2015, 2016 e 2017 no cenário político brasileiro. Foi quando vimos com certa insistência, em meio à crise política e econômica, a repetição do lema "Há a necessidade de se retomar o crescimento econômico". Tal repetição apresenta algumas variações na formulação, tais como "O Brasil precisa retomar o rumo do crescimento", "Precisamos voltar a crescer", "A economia está estagnada", "O desenvolvimento precisa ser retomado", "O Brasil não pode ficar parado" e outras $^{10}$. Tais discursos ocorreram e ocorrem principalmente no entrelaçamento entre grandes mídias e personalidades da vida política do país. Durante o processo de julgamento parlamentar de Dilma Roussef, eles se tornaram armas expressivas para justificar o fim de seu governo (com outros problemas sendo também articulados). Portanto temos, nessas breves sentenças, dois elementos antes mencionados: de um lado, o discurso da necessidade, apelando para toda a sorte de diagnósticos de economistas e planejadores que, supostamente embasados cientificamente, demonstravam tecnicamente a crise que se assolava e o modo de superação. De outro, o próprio desenvolvimento, aqui claramente equalizado a crescimento econômico, como um termo do repertório e bastante apropriado ao momento, já que em tese ninguém será contra o desenvolvimento do Brasil.

O rumo não esperado diz respeito ao problema da conjugação mais uma vez de desenvolvimento e liberalismo, pois, ao passo que o discurso do crescimento é evocado por setores governamentais do mandato de Michel Temer, mecanismos de ação tipicamente liberais são trazidos à cena, além de reformas, planos de privatização, diminuição do gasto público e outros.

Por que razão as questões econômicas foram trazidas ao centro do palco? Uma mistura de retórica, discurso da necessidade, justificativa da calculabilidade como técnica que dá o veredicto ao governo Dilma Roussef, daí que, ainda no mandato da ex-presidente, o que muito se escutou foi "O Brasil não pode ficar parado". Política e ciência (econômica) mescladas, mas sempre no tom de um diagnóstico racional que deveria fundamentar as mudanças. Tanto parece ser o caso que, em seu discurso de defesa no Senado em 2016, Dilma se mostra estupefata

\footnotetext{
${ }^{10}$ Várias fontes corroboram tais informações destacadas entre aspas, especialmente as relativas à mídia comercial brasileira. Somente no que diz respeito a jornais, diferentes notícias atestam tal insistência, tais como as disponíveis a seguir:

http://g1.globo.com/politica/noticia/2016/11/temer-pessoas-nao-percebem-que-estamos-em-recessao-profunda.html https://www1.folha.uol.com.br/mercado/2017/04/1876495-governo-nao-pode-ficar-parado-diz-temer-adeputados.shtml

https://brasil.elpais.com/brasil/2017/11/07/opinion/1510071449_865256.html

http://www.correiodopovo.com.br/Noticias/Politica/2017/09/627491/Brasil-esta-voltando-para-o-trilho-dodesenvolvimento,-diz-Temer-na-China

http://www.correiodopovo.com.br/Noticias/Politica/2017/08/626233/Aliados-de-Temer-minam-pretensao-deMeirelles

http://www1.folha.uol.com.br/mercado/2018/01/1952924-em-davos-temer-vende-reformas-e-prometeestabilidade-apos-eleicao.shtml

http://www.valor.com.br/politica/5390755/temer-equilibrio-fiscal-resulta-na-queda-da-inflacao-e-dos-juros
} 
com a questão acusatória de que três decretos de seu governo teriam sido responsáveis pelos milhões de desempregados no Brasil nos últimos anos. E alguns meses depois, Michel Temer fala ao público em Nova York sobre o país estar pronto para retomar o crescimento, convidando os investidores estrangeiros para tais inversões. Mais alguns meses adiante, em janeiro de 2018, Temer discursava no Fórum Econômico Mundial de Davos e desejava passar uma nova imagem deste Brasil após governos do PT, afirmando no fim de sua intervenção a uma plateia esvaziada: "Nosso país saiu mais forte da crise e retornou ao trilho do desenvolvimento"11.

De qualquer modo, para um leitor minucioso, não é ocasional que a insistência no problema "O Brasil não pode ficar parado" evoque um tipo distinto de dominação daquele que estamos acostumados a falar, particularmente examinando os séculos de história de nosso país. O cenário mais comum e repetido é o do poder das elites agrárias ou urbanas, ambas conservadoras, e o quanto emperram mudanças sociais rumo à modernidade. Não parece ser isto que está em jogo aqui, trata-se quem sabe de uma combinação entre um sistema conservador com uma lógica própria que se vale de transformações sociais. Seguindo mais uma vez as pistas do sociólogo francês: "Uma das características dos dispositivos gestionários é garantir, se for possível por meios formalmente pacíficos, uma forma de dominação que - como já foi dito - não só não impede a mudança, mas que se exerce mesmo por meio da mudança" (BOLTANSKI, 2013, p. 452).

É valoroso observar o quanto as mudanças servem a algum fim e, especialmente, o que ela própria efetua e justifica. Ela opera nas dimensões científicas e no discurso administrativo: faz incidir sobre a política que tais mudanças são necessárias e justificáveis, portanto podem envolver - e em geral envolvem - muitos custos e sacrifícios ${ }^{12}$.

\section{A POTENCIALIDADE DE OUTRAS LINGUAGENS: CONSIDERAÇÕES FINAIS}

Quando na aurora da "era pós-colonial" no século XX as mais recentes ex-colônias foram convocadas a sentarem-se à mesa das nações (FERGUSON, 2005), o desenvolvimento foi elevado à graça, tornando-se - para além da tutela ou da violência colonial - o mantra a ser proferido por todos que quisessem algum dia "chegar a algum lugar", tanto fazendo se no industrialismo socialista ou no capitalismo sob égide norte-americana. Não estávamos aqui diante daquela situação que Rancière (1996) sugere ser fundadora da política? Para o autor francês (RANCIÈRE, 1996), a igualdade das pessoas livres é o princípio da democracia, não só como condição, mas o pressuposto que todos são iguais e livres, e não que esta venha um dia a ser atingida. A questão

\footnotetext{
${ }^{11}$ Discurso em Davos está disponível na íntegra em http://www1.folha.uol.com.br/mercado/2018/01/1952924-emdavos-temer-vende-reformas-e-promete-estabilidade-apos-eleicao.shtml (acesso: 24 jan. 2018).

12 Embora se apresentem como tipicamente modernas e orientadas a fins racionais, não significa que razões mais remotas e articuladas a uma trama complexa de convicções não estejam em jogo, por isso mesmo a facilidade com que se transita entre política e técnica, gestão e "crença". Um dos filósofos mais produtivos da atualidade, Giorgio Agamben, tem nos levado a pensar o quanto as categorias políticas e econômicas do Ocidente originamse de conceitos teológicos cristãos (reflexão também feita por alguns de seus predecessores) e que tal matriz se atualiza em práticas presentes. Para tal, um argumento de Talal Asad, também pesquisador do entrelaçamento de religião e modernidade, é elucidativo e serve para pensarmos a relação entre colonialismo e desenvolvimento: "De qualquer modo, quando os europeus querem fazer do mundo sua própria imagem não é necessariamente algo a ser desacreditado como não generoso. Se uma pessoa acredita que é a fonte da salvação, o desejo para fazer os outros um reflexo de si mesmo não é maldoso mesmo que seja por meio de práticas terríveis que este desejo seja colocado em ação. Além do mais, em uma tradição que relaciona dor ao ganho, infligir sofrimento aos outros não é em si próprio algo repreensível: isto deve ser condenado somente quando é gratuito - quando a dor como meio passa do aceitável [...] (ASAD, 1993, p. 12).
} 
vem a ser quem pode ser contado fazendo parte do mundo. O problema neste ponto de partida é justamente quais condições fundamentam tal ponto inicial. Além de ter p̉oucas possibilidades de se opor à receita dos primeiro-mundistas (o desenvolvimento capitalista em especial), as estruturas coloniais mantinham-se em diferentes escalas.

A ajuda e a cooperação internacional tornam-se centrais para a máquina do desenvolvimento. Em um estudo impactante, Kothari (2005) mostrou que a maior parte dos profissionais especialistas do campo da ajuda internacional no Reino Unido era oriunda das ex-colônias inglesas, já que possuíam experiência e conhecimento dos códigos culturais locais para atuarem nos países recém-independentes. Assim que tal ruptura entre colonialismo e desenvolvimento na história não é tão claro.

Tanto efeito podemos sentir, que em um livro impressionante, intitulado não ao acaso de Dead Aid [Ajuda Morta], a economista nascida na Zâmbia, Dambisa Moyo, escreve sem problemas: parem de ajudar o continente africano. O impacto de suas palavras justifica a longa citação.

Nos últimos cinquenta anos, mais de 1 trilhão de dólares em programas de ajuda para o desenvolvimento foi transferido dos países ricos para a África. Somente na última década, no âmbito do Live 8, Make Poverty History, os Objetivos do Milênio, Millennium Challenge Account, the Africa Commission e o Encontro de 2005 do G7 (só para nomear alguns), milhões de dólares foram juntados a cada ano nos países ricos como apoio ao trabalho de caridade para África. Nós fomos feitos para acreditar que isto é o que se deve fazer. [...]

No fundo de toda sensibilidade liberal há um senso profundo de que em um mundo de incerteza moral há uma ideia sagrada, uma crença que não pode ser comprometida: o rico deve ajudar o pobre e a forma deste ato deve ser a ajuda. [...]. A ajuda se tornou parte da indústria do entretenimento. [...]

Mas 1 trilhão de dólares em assistência ao desenvolvimento durante as últimas várias décadas colocou a população africana em melhores condições? Não. De fato, no mundo todo os assistidos por esta ajuda estão em piores condições; muito piores. A ajuda fez com que os pobres se tornassem mais pobres e crescessem mais devagar. E ainda, a ajuda se mantém como uma peça central da política de desenvolvimento atual e uma das grandes ideias do nosso tempo. A noção de que a ajuda pode aliviar a pobreza sistêmica, e que já fez algo para aliviá-la, é um mito. (MOYO, 2009, p. xviii-xix).

A ajuda internacional na qual estamos imersos e realizada durante décadas não proporcionou nada de bom, chega, esta é a conclusão da autora. Novamente, parece que chegamos ao mesmo ponto: quem tem possibilidade de falar e ser escutado quando se trata das consequências do desenvolvimento? Note-se que uma comparação com o que Goldman (2005) escreveu e que foi destacado no início deste artigo é iluminadora: o dinheiro para o desenvolvimento "viaja", isto é certo; onde vai parar, quem se apropria e o que se faz com ele é outra história.

A arquitetura do desenvolvimento e da ajuda internacional se estrutura então de maneira que tenhamos pouco acesso ao cinismo, que Michael Goldman (2005) expõe nas altas esferas de decisão e organização do desenvolvimento, mas que sejamos integralmente tocados pela moral da boa intenção da caridade. O quanto ambas estão em conexão é algo difícil de ver e sobretudo de decifrar seus fluxos e formas de organização. Mas há também, nas pontas dos processos, grupos organizados e movimentos sociais nos alertando sobre a violência do desenvolvimento nas comunidades locais, mesmo que as premissas da necessidade e da justificativa estejam sendo fundamentadas em explicações científicas. Algo que parece escapar à violência, mas também se apresenta como mecanismo de dominação e de silenciamento das possíveis resistências. 
Pelo menos em um ponto de vista, os escritos de Dambisa Moyo (2009) em Dead Aid se aparentam aos desabafos de Alberto Pizango (2009), líder indígena peruano: tanto um como outra se apropriam do caráter aberto da linguagem do desenvolvimento para demarcarem um conteúdo a ele que seja satisfatório. Evidentemente, são casos difíceis de comparar, mas ambos tentam organizar os excessos dos significados de modo inteligente, ambos procuram expor outras possibilidades, outras potencialidades. No caso mais radical, estabelece-se uma possível reengenharia que reverte as prioridades e talvez não se possa mais falar em desenvolvimento, afinal. Expor outras possibilidades é apontar para outras linguagens que escapem do discurso monocórdio de nossos tempos.

A linguagem do desenvolvimento tem uma marca impressionante: sabe-se o que se quer fazer pelos outros, não importa quais custos e sacrifícios; os supostos beneficiários não sabem e não conhecem os caminhos, e alguns (os de fora, em geral) têm o privilégio de saber e falar por eles. Grandes projetos e discursos tecnocientíficos são mais persuasivos que as práticas inventivas locais.

Esses limites supõem que, se no Brasil há uma linguagem corrente na política em que se fala por meio das categorias vinculadas ao desenvolvimento, há também outras linguagens e potencialidades. Muitas vezes não as percebemos, mas elas estão sendo faladas e desenham mundos.

\section{REFERÊNCIAS}

ARCE, Alberto; LONG, Norman. Reconfiguring modernity and development from an anthropological perspective. In: ARCE, Alberto; LONG, Norman (Ed.). Anthropology, development and modernities: exploring discourses, counter-tendencies and violence. London/New York: Routledge, 2000. p. 1-31.

ASAD, Talal. Genealogies of religion: discipline and reasons of power in Christianity and Islam. Baltimore: The Johns Hopkins University Press, 1993.

BOLTANSKI, Luc. Sociologia da crítica, instituições e o novo modo de dominação gestionário. Sociologia \& Antropologia, Rio de Janeiro, v. 3, n.6, p. 441-63, 2013.

BRIGG, Morgan. Post-development, Foucault and the colonisation metaphor. Third World Quarterly, v. 23, n. 3, p. 421-36, 2002.

CARDOSO, Fernando H. O modelo político brasileiro e outros ensaios. São Paulo: DIFEL, 1972.

CHAUÍ, Marilena. Cultura e democracia: o discurso competente e outras falas. São Paulo: Moderna, 1980.

DOUGLAS, Mary; ISHERWOOD, Baron. O mundo dos bens: para uma antropologia do consumo. Rio de Janeiro: Ed. UFRJ, 2006.

ESCOBAR, Arturo. La invención del tercer mundo: construcción y deconstrucción del desarrollo. Caracas: El Perro y la Rana, 2007.

ESTEVA, Gustavo. Development. In: SACHS, Wolfgang (Ed.). The development dictionary: a guide to knowledge as power. London: Zed Books, 1992. p. 6-25.

FERGUSON, James. Anthropology and its Evil Twin: "Development" in the Constitution of a Discipline. In: EDELMAN, Marc; HAUGERUD, Angelique (Ed.). The anthropology of development and globalization: from classical political economy to contemporary neoliberalism. Malden: Blackwell, 2005. p. 140-53. 
FERGUSON, James. The anti-politics machine: "development", depoliticization, and bureaucratic power in Lesotho. Cambridge/New York: Cambridge University Press, 1990.

FONSECA, Pedro Cezar Dutra. Gênese e precursores do desenvolvimentismo no Brasil. Pesquisa e Debate, São Paulo, v. 15, n. 2(26), p. 225-56, 2004.

GARCÍA PÉREZ, Alan. Receta para acabar con el perro del hortelano. El Comercio, Lima, p. a6, 25 nov 2007.

GOLDMAN, Marcio. O fim da antropologia. Novos Estudos Cebrap, São Paulo, n. 89, p. 195-211, 2011.

GOLDMAN, Michael. Imperial nature. The World Bank and struggles for social justice in the age of globalization. New Haven/London: Yale University Press, 2005.

HOLBRAAD, Martin; PEDERSEN, Morten. The ontological turn: an anthropological exposition. Cambridge: Cambridge University Press, 2017.

KAPOOR, Ilan. The postcolonial politics of development. London: Routledge, 2008.

KIRSCH, Stuart. Reverse anthropology: indigenous analysis of social and environmental relations in New Guinea. Stanford: Stanford University Press, 2006.

KOTHARI, Uma. From colonial administration to development studies: a post-colonial critique of the history of development studies. In: KOTHARI, Uma (Ed.). A radical history of development studies: individuals, institutions and ideologies. Londres: Zed Books, 2005. p. 47-66.

LACLAU, Ernesto; MOUFFE, Chantal. Hegemony and socialist strategy: towards a radical democratic politics. London: Verso, 1985.

LAMOUNIER, Bolivar. Apontamentos sobre a questão democrática brasileira. In: ROUQUIÉ, A.; LAMOUNIER, B.; SCHVARZER, J. (Org.). Como renascem as democracias. São Paulo: Brasiliense, 1985. p. 105-40.

MOYO, Dambisa. Dead aid: why aid is not working and how there is a better way for Africa. New York: Farrar, Straus and Giroux, 2009.

NUSTAD, Knut. Development: the devil we know? In: ZIAI, Aram (Ed.). Exploring post-development: theory and practice, problems and perspectives. London: Routledge, 2007. p. 35-46.

PAREDES PEÑAFIEL, Adriana. Da mina de Socavão à mina a céu aberto: os novos pactos no caso do centro de mineração de Hualgayoc, Cajamarca, Peru. Caderno Eletrônico de Ciências Sociais, Vitória, ES, v. 5, n. 1, p. 115-35, 2017.

PAREDES PEÑAFIEL, Adriana; RADOMSKY, Guilherme F. W. Dilemas da interculturalidade e da biodemocracia: o massacre em Bagua, Amazônia peruana. Amazônica: Revista de Antropologia, Belém, PA, v. 3, n. 1, p. 60-87, 2011.

PARFITT, Trevor. Are the Third World poor Homines Sacri? Biopolitics, sovereignty, and development. Alternatives, v. 34, n.1, p. 41-58, 2009.

PERROT, Dominique. Quem impede o desenvolvimento "circular"? (Desenvolvimento e povos autóctones: paradoxos e alternativas). Cadernos de Campo, São Paulo, n. 17, p. 219-32, 2008.

PIZANGO, Alberto. Los nativos no son manipulados y el viaje de Simon sería en vano (entrevista concedida à Rocío Maldonado). La Republica, Lima, p. 04, 24 maio 2009. 
RAHNEMA, Majid; BAWTREE, Victoria (Ed.). The post-development reader. Londres: Atlantic Highlands, 1997.

RANCIÈRE, Jacques. O desentendimento: política e filosofia. São Paulo: Editora 34, 1996.

RIBEIRO, Gustavo L. Poder, redes e ideologia no campo do desenvolvimento. Novos Estudos CEBRAP, São Paulo, 80, p. 109-25, mar. 2008.

RIST, Gilbert. The history of development: from western origins to global faith. 3. ed. Londres: Zed Books, 2008.

SALLUM JÚNIOR, Brasílio; GOULART, Jeferson. O Estado brasileiro contemporâneo: liberalização econômica, política e sociedade nos governos FHC e Lula. Revista de Sociologia e Política, Curitiba, v. 24, n. 60, p. 115-35, dez. 2016.

SALLUM JÚNIOR, Brasílio. Liberalismo e desenvolvimentismo no Brasil dos anos 90. In: ARBIX, Glauco et al. (Org.). Razões e fiç̧ões do desenvolvimento. São Paulo: Editora Unesp/Edusp, 2001. p. 311-47.

SPIVAK, Gayatri C. Pode o subalterno falar? Belo Horizonte: Ed. UFMG, 2010.

STOREY, Andy. Post-development theory: romanticism and Pontius Pilate politics. Development, v. 43, n. 4, p. 40-6, 2000.

STRATHERN, Marylin. O gênero da dádiva: problemas com as mulheres e problemas com a sociedade na Melanésia. Campinas, SP: Ed. da Unicamp, 2006.

SYLVESTER, Chris. Bare life as a development/postcolonial problematic. The Geographical Journal, v. 172, n. 1, p. 66-77, 2006.

WAGNER, Roy. A invenção da cultura. São Paulo: Cosac Naify, 2010.

ZIAI, Aram. Post-development: premature burials and haunting ghosts. Development and Change, v. 46, n. 4, p. 833-54, 2015.

ZIAI, Aram. The ambivalence of post-development: between reactionary populism and radical democracy. In: ZIAI, Aram (Ed.). Exploring post-development: theory and practice, problems and perspectives. London: Routledge, 2007. p. 111-28.

ŽIŽEK, Slavoj. A visão em paralaxe. São Paulo: Boitempo, 2008.

\section{Sobre o autor:}

Guilherme Francisco Waterloo Radomsky - Doutor em Antropologia Social pela Universidade Federal do Rio Grande do Sul (UFRGS). Professor do departamento de Sociologia e dos Programas de Pós-graduação em Sociologia (PPGS/UFRGS) e em Desenvolvimento Rural (PGDR/UFRGS) da UFRGS. E-mail: guilherme.radomsky@ufrgs.br, Orcid: http://orcid.org/0000-0002-3756-4286 
